\title{
Existence of a unique equilibrium in asymmetric contests with interdependent preferences
}

\author{
Shumei Hirai \\ Department of Economics, Seinan Gakuin University, Fukuoka, Japan
}

Email address:

hirai@seinan-gu.ac.jp, hirai-shumei@jcom.home.ne.jp

To cite this article:

Shumei Hirai. Existence of a Unique Equilibrium in Asymmetric Contests with Interdependent Preferences. International Journal of Economic Behavior and Organization. Special Issue: Recent Developments of Economic Theory and Its Applications. Vol. 3, No. 2-1, 2015 , pp. 10-14. doi: $10.11648 /$ j.ijebo.s.2015030201.13

\begin{abstract}
By relaxing the common assumption of purely self-interested preferences in contests, we study contests in which players care not only about their own material payoffs but also about other players' payoffs, a scenario we term "interdependent preferences." In addition, we identify three possible types of heterogeneity among players in contests. First, players may have asymmetric preferences toward each other. Second, players may have various abilities to convert expenditures to productive efforts. Third, players may face various financial constraints. This paper presents a proof of the existence and uniqueness of a pure Nash equilibrium in asymmetric contests with interdependent preferences.
\end{abstract}

Keywords: Contests, Interdependent Preferences, Existence and Uniqueness

\section{Introduction}

A contest is a strategic game in which players put in serious efforts to increase their probability of winning a given prize. Since the pioneering work of [32] and [14], a large and growing body of literature has emerged that examines the theory and application of contests. ${ }^{1}$ One of the most important questions is the existence and uniqueness of a pure Nash equilibrium: if the equilibrium is unique, then a self-constrained theory exists that can predict the contest's outcome. Moreover, uniqueness is crucial for comparative statics analysis, which allows one to obtain qualitative results The existence of such a unique equilibrium has been extensively studied under the assumption of pure self-interest; see e.g., [25], [30], [13], and [36].

However, in some cases, players (contestants) may care not about their own material payoffs but also about the other players' payoff. We call them interdependent preferences. For instance, evaluations of management activities are often based on relative as well as absolute performances. Furthermore, outperforming managers often obtain good positions through the management job market. Thus, firms'

\footnotetext{
${ }^{1}$ See the excellent survey by [12]. In addition, as was pointed out in [30] noncooperative contests are formally equivalent to Cournot oligopolies with isoelastic (hyperbolic) price functions. Accordingly, results on the contests have also some bearing on the field of industrial organization.
}

managers have negatively interdependent preferences. ${ }^{2}$ In U.S. sports leagues, such as Major League Baseball and the National Football League, some teams enjoy certain mutual revenue sharing arrangements. Under revenue sharing in sporting contests, money obtained by one team is partially redistributed to other teams. ${ }^{3}$ Given the peculiarities of sporting contests, each team's objective function includes its competitor's payoff. Under these conditions, a team would certainly also care about the other teams' payoff ([19]). Apart from these practical situations, many laboratory (experimental) works have identified spiteful as well as altruistic behavior ([7]; [5]; [8]). Both behaviors are closely related to players' objective functions based on relative performance.

Two theoretical contributions concerning the theory of contests with interdependent preferences are [16] and [26]. They analyze rent-seeking contests with a semi-symmetric case, in which some players are absolute payoff maximizers while others are also concerned about their relative standing. As a result, those players with negatively interdependent preferences experience a strategic advantage in $n$-player

\footnotetext{
2 This framework was originally proposed by [33] and [15] in the context of an oligopoly. There is an increasing body of literature on strategic delegation in contests ( e.g. [3]; [21]; [22]).

${ }^{3}$ The main objective of revenue sharing is guaranteeing a reasonable competitive balance in a league. See the excellent survey by [31].
} 
contests. Another contribution to this field of research is [27], which examines the effect of preferences that are not purely self-interested (altruism or envy) on equilibrium rent-seeking efforts and net payoffs in a two-player contest. In these studies, players are assumed to have identical abilities and a budget large enough such that the budget constraints are not binding at all. In addition, they analyze asymmetric contests with heterogeneity of preferences about other players' payoffs. However, the authors assume either semi-symmetric cases or two players.

In this paper, we introduce three types of heterogeneity among players into $n$-player contests with interdependent preferences. First, each player may have a different preference regarding its competitors' payoffs (e.g., [20]). Second, each player may have a different ability to convert expenditures to productive efforts (e.g., [2]). Third, players may face different financial constraints (e.g., [9]). Following the same steps as in [13] and [18], we prove that there exists a unique asymmetric pure Nash equilibrium in a contest with these three types of heterogeneity among players.

The rest of the paper is organized as follows. Section 2 explains the basic model and the assumptions. In Section 3, we prove the existence of a unique pure Nash equilibrium. Concluding remarks are presented in Section 4.

\section{The Model}

Let $n$ be the number of players in a contest. Denote $V>0$ as the common prize value. ${ }^{4}$ Players are assumed to be risk-neutral. If $x_{i}$ is player $i$ 's expenditure in the contest, then the probability of winning the prize is given as

$$
p_{i}=\frac{f_{i}\left(x_{i}\right)}{\sum_{j=1}^{n} f_{j}\left(x_{j}\right)}
$$

where $f_{i}(\cdot)$ is an increasing function for all $i .^{5}$ [30] called $f_{i}(\cdot)$ player $i$ 's production function for lotteries. We assume that each player has finite wealth $\tilde{L}_{i}$, which is the budget constraint on what player $i$ can spend on contests: $x_{i} \leq \tilde{L}_{i}$. Then, we adopt the following assumption, which is in line with most existing researches.

Assumption 1. For all $i$, the function $f_{i}$ satisfies the following conditions:

$f_{i}$ is twice differentiable, $f_{i}(0)=0$, and $f_{i}^{\prime}\left(x_{i}\right)>$ $0, f_{i}^{\prime \prime}\left(x_{i}\right) \leq 0$ for all $x_{i} \in\left[0, \tilde{L}_{i}\right]$.

Note that the players' production functions and budgets do not necessarily have to be identical. A particularly well-studied form of $f_{i}$ is $f_{i}\left(x_{i}\right)=a_{i} x_{i}^{r}$, where $r>0$ and $a_{i}>0$. This asymmetric form was given an axiomatic foundation by [10] by following an earlier axiomatization given by [28] in a symmetric form.

For simplicity, the variables are reordered by setting $y_{i}=f_{i}\left(x_{i}\right)$ for each $i$. Accordingly, the function $f_{i}(\cdot)$ may be considered as transforming individual expenditure $x_{i}$ into

\footnotetext{
${ }^{4}$ Each player may have a different valuation for the prize (e.g., [17]). However, it is left to future research to investigate this more general case.

${ }^{5}$ Another interpretation of $p_{i}$ is that each player $i$ receives a fraction $\frac{f_{i}\left(x_{i}\right)}{\sum_{j=1}^{n} f_{j}\left(x_{j}\right)}$ of the contested prize.
}

effective effort $y_{i}$. We will henceforth refer to $x_{i}$ as expenditure, and $y_{i}$ as effort, of player $i$, respectively. Since $f_{i}$ is monotonic, it has a well-defined inverse function, $g_{i}\left(y_{i}\right)=f_{i}^{-1}\left(y_{i}\right)$. Let $L_{i}=f_{i}\left(\tilde{L}_{i}\right)$ be player $i$ 's maximum effort due to his or her budget constraint. Then, Assumption 1 (A.1 in what follows) implies that

$$
g_{i}(0)=0 \text {, and } g_{i}^{\prime}\left(y_{i}\right)>0, g_{i}^{\prime \prime}\left(y_{i}\right) \geq 0 \text { for all } y_{i} \in\left[0, L_{i}\right] \text {. }
$$

Function $g_{i}\left(y_{i}\right)$ describes the total cost to player $i$ for generating level $y_{i}$ of effort.

Then, the (expected) material payoff of player $i$ can be described by

$$
\pi_{i}\left(y_{i}, Y_{-i}\right)=p_{i} V-x_{i}=\frac{y_{i}}{y_{i}+Y_{-i}} V-g_{i}\left(y_{i}\right)
$$

where $Y_{-i}=\sum_{j \neq i}^{n} y_{j}$. If all $y_{i}=0$, then $\pi_{i}$ is defined to be zero. $^{6}$ As in [27], we introduce interdependent preferences in the model by representing each player's objective function as

$$
F_{i}\left(y_{i}, Y_{-i}\right)=\pi_{i}-\alpha_{i} \frac{1}{n} \sum_{j=1}^{n} \pi_{j}
$$

where $\alpha_{i}$ represents the weight that player $i$ gives for the average payoff of all players when player $i$ takes its own decisions. ${ }^{7}$ We can interpret $\alpha_{i}$ as a parameter indicating player $i$ 's degree of altruism $\left(\alpha_{i}<0\right)$ or envy $\left(\alpha_{i}>0\right){ }^{8}$ Since these types of preferences depend not only on the absolute material payoff, but also on the relative material payoff, we call them utility, which represents the players' interdependent preferences.

In the following discussion, we adopt the next assumption. Assumption 2. $\alpha_{i}<n, i=1, \cdots, n$.

A.2, together with A.1, ensures that a player's utility is a strictly concave function of her own efforts.

We can therefore rewrite the utility of player $i$ as

$F_{i}\left(y_{i}, Y_{-i}\right)=$

$\frac{y_{i}}{y_{i}+Y_{-i}} V-\lambda_{i} g_{i}\left(y_{i}\right)-\left(1-\lambda_{i}\right)\left(V-\sum_{j \neq i}^{n} g_{j}\left(y_{j}\right)\right)$,

where

$$
\lambda_{i}=1-\frac{\alpha_{i}}{n}
$$

From A.2, we have $\lambda_{i}>0$. Player $i$ is assumed to maximize (5) with respect to $y_{i}$ subject to $y_{i} \in\left[0, L_{i}\right]$. Our analysis of contests is formulated as a simultaneous-move game and the solution concept we use throughout paper is that of a pure Nash equilibrium.

\section{Existence Analysis}

We can now calculate the best response of player $i$. Assume first that $Y_{-i}=0$, so that the other players do not spend positive amounts of resources on contest activities. Then

\footnotetext{
${ }^{6}$ Assuming $\pi_{i}$ to be $(1 / n) V$ instead of zero does not affect the following analysis.

${ }^{7}$ Excluding $i$ 's payoff from the average will result in an equivalent measure.

${ }^{8}$ Another interpretation of $\alpha_{i}$ can be found in the review by [4, Sect.4.5] and [23].
} 


$$
F_{i}\left(y_{i}, Y_{-i}\right)= \begin{cases}0 & \text { if } y_{i}=0, \\ \left(V-g_{i}\left(y_{i}\right)\right) \lambda_{i} & \text { if } y_{i}>0 .\end{cases}
$$

In this case, player $i$ has no best choice; however it is in her interest to select a positive value of $y_{i}$ that is nevertheless as small as possible, i.e., player $i$ 's best response $R_{i}\left(Y_{-i}\right)$ does not exist for $Y_{-i}=0$. Therefore, no pure-strategy Nash equilibrium exists. Hence, it suffices to consider the case where $Y_{-i}>0$ for all $i$.

If $Y_{-i}>0$, so that the other players spend positive amounts of resources on contest activities, then

$$
\frac{\partial F_{i}}{\partial y_{i}}=\frac{Y_{-i}}{\left(y_{i}+Y_{-i}\right)^{2}} V-\lambda_{i} g_{i}^{\prime}\left(y_{i}\right)
$$

and under assumptions A.1 and A.2, we have

$$
\frac{\partial^{2} F_{i}}{\partial y_{i}^{2}}=-\frac{2 Y_{-i}}{\left(y_{i}+Y_{-i}\right)^{3}} V-\lambda_{i} g_{i}^{\prime \prime}\left(y_{i}\right)<0 .
$$

Hence $F_{i}$ is strictly concave in $y_{i}$. The utility functions' concavity implies that the best response functions can be obtained in the form

$$
R_{i}\left(Y_{-i}\right)= \begin{cases}0 & \text { if } \frac{V}{Y_{-i}}-\lambda_{i} g_{i}^{\prime}(0) \leq 0, \\ L_{i} & \text { if } \frac{Y_{-i}}{\left(L_{i}+Y_{-i}\right)^{2}} V-\lambda_{i} g_{i}^{\prime}\left(L_{i}\right) \geq 0, \\ y_{i}^{*} & \text { otherwise, }\end{cases}
$$

where $y_{i}^{*}$ is the unique solution of the strictly monotonic equation

$$
\frac{Y_{-i}}{\left(y_{i}+Y_{-i}\right)^{2}} V-\lambda_{i} g_{i}^{\prime}\left(y_{i}\right)=0
$$

in the interval $\left(0, L_{i}\right)$. Note that because of our assumptions, the left-hand side of (9) strictly decreases and is continuous in $y_{i}$, positive at $y_{i}=0$, and negative at $y_{i}=L_{i}$; therefore, a unique solution, $R_{i}\left(Y_{-i}\right)$ exists.

We then can rewrite the best responses as functions of the aggregate effort of all players. Following [35], we call this function the inclusive reaction function of player $i$, which was proposed by [29] and others to study Cournot equilibria and other aggregative games. From (8) we have

$$
\tilde{R}_{i}(Y)= \begin{cases}0 & \text { if } \frac{V}{Y}-\lambda_{i} g_{i}^{\prime}(0) \leq 0 \\ L_{i} & \text { if } \frac{Y-L_{i}}{Y^{2}} V-\lambda_{i} g_{i}^{\prime}\left(L_{i}\right) \geq 0 \\ y_{i}^{* *} & \text { otherwise }\end{cases}
$$

where $y_{i}^{* *}$ solves the following equation:

$$
\frac{Y-y_{i}}{Y^{2}} V-\lambda_{i} g_{i}^{\prime}\left(y_{i}\right)=0
$$

in the interval $\left(0, L_{i}\right)$. Notice that in the third case of (10), the left-hand side is positive at $y_{i}=0$, negative at $y_{i}=L_{i}$, and strictly decreasing, since it has a negative derivative given by

$$
\frac{\partial}{\partial y_{i}}\left\{\frac{Y-y_{i}}{Y^{2}} V-\lambda_{i} g_{i}^{\prime}\left(y_{i}\right)\right\}=-\frac{V}{Y^{2}}-\lambda_{i} g_{i}^{\prime \prime}\left(y_{i}\right)<0,
$$

where the sign comes from assumptions A.1 and A.2. Therefore, a unique solution of equation (11) exists, which is a continuously differentiable function of $Y>0$ by the implicit function theorem. Then, consider the single-variable equation

$$
\sum_{i=1}^{n} \tilde{R}_{i}(Y)-Y=0,
$$

which must hold at an equilibrium. The left-hand side, denoted by $H(Y)$, has the following properties. It is continuous, since all $\tilde{R}_{i}(Y)$ are continuous; $H(Y) \geq 0$ for sufficiently small values of $Y$, since $\tilde{R}_{i}(Y) \geq 0$ for all $i$; and $H\left(\sum_{i=1}^{n} L_{i}\right) \leq 0$, since $\tilde{R}_{i}(Y) \leq L_{i}$. Therefore, at least one solution exists.

To discuss the equilibrium's uniqueness, we will examine the properties of player $i$ 's share function $S_{i}(Y)=\tilde{R}_{i}(Y) / Y$, which is proposed by [13]. Therefore, consider the following function:

$$
h_{i}\left(Y, s_{i}\right)=\frac{V}{Y}\left(1-s_{i}\right)-\lambda_{i} g_{i}^{\prime}\left(s_{i} Y\right)
$$

with $s_{i}=y_{i} / Y$. The function $h_{i}$ is the marginal utility of player $i$ expressed in terms of aggregate effort and share. Notice that under assumptions A.1 and A.2

$$
\frac{\partial h_{i}}{\partial Y}=-\frac{V}{Y^{2}}\left(1-s_{i}\right)-\lambda_{i} g_{i}^{\prime \prime} s_{i}<0,
$$

as $s_{i} \leq 1$. Furthermore,

$$
\frac{\partial h_{i}}{\partial s_{i}}=-\frac{V}{Y}-\lambda_{i} g_{i}^{\prime \prime} Y<0 .
$$

Hence, $h_{i}\left(Y, s_{i}\right)$ decreases in both variables, and this is obtained from player $i$ 's inclusive reaction function (10) and equation (11) that we obtain

$$
S_{i}(Y)= \begin{cases}0 & \text { if } h_{i}(Y, 0) \leq 0, \\ L_{i} / Y & \text { if } h_{i}\left(Y, L_{i} / Y\right) \geq 0, \\ s_{i}^{*} & \text { otherwise }\end{cases}
$$

where $s_{i}^{*}$ is the unique solution of equation

$$
h_{i}\left(Y, s_{i}\right)=0
$$

in the interval $\left(0, L_{i} / Y\right)$. Note that if the first case of (14) occurs, then by the monotonicity of $h_{i}\left(Y, s_{i}\right)$, neither case 2 nor 3 of (14) can occur, and if either case 2 or 3 holds, then the first case must not occur. Hence, for a given value of $Y>0$, exactly one case will hold. The left-hand side of equation (15) is positive at $s_{i}=0$, negative at $s_{i}=L_{i} / Y$, and strictly decreases in $s_{i}$. Therefore, there is a unique solution $s_{i}^{*}$, which is differentiable by the implicit function theorem.

In our further analysis, we will need the derivative of the share function. By differentiating equation (15) with respect to $Y$ and considering $s_{i}=S_{i}(Y)$, we obtain

$$
-\frac{V}{Y^{2}}\left(1-s_{i}\right)-\frac{V}{Y} S_{i}^{\prime}-\lambda_{i} g_{i}^{\prime \prime} S_{i}^{\prime}-\lambda_{i} g_{i}^{\prime \prime} s_{i}=0,
$$

which implies that 


$$
S_{i}^{\prime}(Y)=-\frac{\left(1-s_{i}\right) V+\lambda_{i} g_{i}^{\prime \prime} s_{i} Y^{2}}{\left(V+\lambda_{i} g_{i}^{\prime \prime} Y\right) Y}<0
$$

The inequality comes from assumptions A.1 and A.2. So, $S_{i}(Y)$ is continuous with both constant and strictly decreasing segments. Finally, equation (12) can be also rewritten as

$$
\sum_{i=1}^{n} S_{i}(Y)-1=0,
$$

where the left-hand side is nonincreasing. Assume that equation (17) can have two different solutions, where $\bar{Y}^{\prime}>\bar{Y}$. Then, $\bar{Y}^{\prime}>0$ and at least two players must be active in the equilibrium. In this case, $S_{i}(\bar{Y})>S_{i}\left(\bar{Y}^{\prime}\right)$, and for all $j \neq i$, $S_{j}(\bar{Y}) \geq S_{j}\left(\bar{Y}^{\prime}\right)$ in accordance with equation (16). Then,

$$
\sum_{i=1}^{n} S_{i}(\bar{Y})>\sum_{i=1}^{n} S_{i}\left(\bar{Y}^{\prime}\right),
$$

which is an obvious contradiction. Therefore, the equilibrium value of $Y$ is unique. Given an equilibrium $\bar{Y}$, the corresponding unique strategy profile $\left(\bar{y}_{1}, \cdots, \bar{y}_{n}\right)$ is found by multiplying $\bar{Y}$ by each player's share evaluated at $\bar{Y}$ : $\bar{y}_{i}=\bar{Y} S_{i}(\bar{Y})$. Hence we proved the following result:

Theorem 1. Under assumptions A.1 and A.2, a unique pure Nash equilibrium exists in asymmetric contests with interdependent preferences.

\section{Conclusions}

This paper provides a proof of the existence of a unique equilibrium in asymmetric contests with interdependent preferences. The techniques and results developed in this paper offer computational methods to find the equilibria [see Eqs. (14) and (17)] and can be applied to many areas, such as labor tournaments, delegation games, sporting contests, and cooperative productions.

In future research, we will examine the effect of preferences that are not purely self-interested (altruism or envy) upon equilibrium efforts and the net payoffs in $n$-player contests. Unfortunately, contests generally feature neither strategic substitutes nor strategic complements $([12])^{9}$. Therefore, the results in [11] or any of the well-known results on games with strategic complementarities do not apply ([34]; [24]). However, more recently, [1] provides comparative static results for the so-called nice aggregative games, where payoff functions are continuous and concave in terms of players' own strategies. The results of [1] may be applied to the model studied here.

\section{Acknowledgements}

The earlier version of this paper was presented at the 2014 autumn meeting of the Japan Association for Applied Economics, Chuo University, Tokyo, Japan, November 15, 2014. The author wishes to thank participants, Kenichi Amaya,

\footnotetext{
${ }^{9}$ The concept of strategic substitution and complementarity are due to [6].
}

Takeshi Ogawa, an associate editor, and an anonymous referee for their invaluable comments and suggestions. The usual disclaimer applies.

This paper is dedicated to Professor Toshikazu Ito on the occasion of his retirement at Ryukoku University.

\section{References}

[1] D. Acemoglu, and M. K. Jensen, "Aggregate comparative statics," Games and Economic Behavior, vol.81, pp. 27-49, 2013.

[2] K. H. Baik, "Effort levels in contests with two asymmetric players," Southern Economic Journal, vol.61, pp.367-378, 1994.

[3] K. H. Baik, and I. G. Kim, "Delegation in contests," European Journal of Political Economy, vol.13, pp.281-298, 1997.

[4] G. I. Bischi, C. Chiarella, M. Kopel, and F. Szidarovszky, Nonlinear Oligopolies: Stability and Bifurcations, Berlin: Springer-Verlag, 2010.

[5] J. Brandts, T. Saijo, and A. Schram, "How universal is behavior? A four country comparison of spite and cooperation in voluntary contribution mechanisms," Public Choice, vol.119, pp.381-424, 2004.

[6] J. I. Bulow, J. D. Geanakoplos, and P. D. Klemperer, "Multimarket oligopoly: Strategic substitutes and complements," Journal of Political Economy, vol.93, pp.488-511, 1985.

[7] T. N. Cason, T. Saijo, and T. Yamato, "Voluntary participation and spite in public good provision experiments: An international comparison," Experimental Economics, vol.5, pp.133-153, 2002.

[8] J. C. Coats, and W. S. Neilson, "Beliefs about other-regarding preferences in a sequential public goods game," Economic Inquiry, vol.43, pp.614-622, 2005.

[9] Y-K. Che, and I. Gale, "Rent dissipation when rent seekers are budget constrained," Public Choice, vol.92, pp.109-126, 1997.

[10] D. J. Clark, and C. Riis, "Contest success functions: An extension," Economic Theory, vol.11, pp.201-204, 1998.

[11] L. C. Corchón, "Comparative statics for aggregative games: The strong concavity case," Mathematical Social Sciences, vol.28, pp.151-165, 1994.

[12] L. C. Corchón, "The theory of contests: A survey", "Review of Economic Design, vol.11, pp.69-100, 2007.

[13] R. Cornes, and R. Hartley, "Asymmetric contests with general technologies," Economic Theory, vol.26, pp.923-946, 2005.

[14] A. Dixit, "Strategic behavior in contests," American Economic Review, vol.77, pp.891-898, 1987.

[15] C. Fershtman, and K. L. Judd, "Equilibrium incentives in oligopoly," American Economic Review, vol.77, pp.927-940, 1987.

[16] T. Guse, and B. Hehenkamp, "The strategic advantage of interdependent preferences in rent-seeking contests," Public Choice, vol.129, pp.323-352, 2006. 
[17] A. L. Hillman, and J. C. Riley, "Political contestable rents and transfers," Economics and Politics, vol.1, pp.17-39, 1989.

[18] S. Hirai, and F. Szidarovszky, "Existence and uniqueness of equilibrium in asymmetric contests with endogenous prizes," International Game Theory Review, vol.15, 1350005 (9 pages), 2013

[19] S. Késenne, The Economic Theory of Professional Team Sports: An Analytical Treatment-Second Edition, Cheltenham, UK: Edward Elgar, 2014.

[20] K. A. Konrad, "Altruism and envy in contests: An evolutionarily stable symbiosis," Social Choice and Welfare, vol.22, pp. 479-490, 2004.

[21] M. Kräkel, "Delegation and strategic incentives for managers in contests," Managerial and Decision Economics, vol.23, pp. 461-470, 2002.

[22] M. Kräkel, and D. Sliwka, "Strategic delegation and mergers in oligopolistic contests," Journal of Economics and Business, vol.58, pp.119-136, 2006.

[23] T. Matsumura, and N. Matsushima, "Competitiveness and stability of collusive behavior," Bulletin of Economic Research, vol.64, pp.s22-s31, 2012.

[24] P. Milgrom, and J. Roberts, "Rationalizability, learning, and equilibrium in games with strategic complementarities," Econometrica, vol.58, pp.1255-1277, 1990.

[25] J. D. Pérez-Castrillo, and T. Verdier, "A general analysis of rent-seeking games," Public Choice, vol.73, pp.335-350, 1992.

[26] T. Riechmann, "An analysis of rent-seeking games with relative-payoff maximizers," Public Choice, vol.133, pp.147-155, 2007.
[27] S. Shaffer, "Contests with interdependent preferences," Applied Economics Letters, vol.13, pp.877-880, 2006.

[28] S. Skaperdas, "Contest success functions," Economic Theory, vol.7, pp.283-290, 1996.

[29] F. Szidarovszky, and S. Yakowitz, "A new proof of the existence and uniqueness of the Cournot equilibrium," International Economic Review, vol.18, pp.787-789, 1977.

[30] F. Szidarovszky, and K. Okuguchi, "On the existence and uniqueness of pure Nash equilibrium in rent-seeking games," Games and Economic Behavior, vol.18, pp.135-140, 1997.

[31] S. Szymanski, "The economics design of sporting contests," Journal of Economic Literature, vol.41, pp.1137-1187, 2003.

[32] G. Tullock, "Efficient rent-seeking," In J. M. Buchanan, R. D. Tollison and G. Tullock (Eds.), Toward a Theory of the Rent-Seeking Society (pp.97-112), College Station: Texas A\&M University Press, 1980.

[33] J. Vickers, "Delegation and the theory of the firm," Economic Journal, vol.95, pp.138-147, 1985.

[34] X. Vives, "Nash equilibrium with strategic complementarities," Journal of Mathematical Economics, vol.19, pp.305-321, 1990.

[35] E, Wolfstetter, Topics in Microeconomics: Industrial Organization, Auctions, and Incentives, Cambridge: Cambridge University Press, 1999.

[36] T. Yamazaki, "On the existence and uniqueness of pure-strategy Nash equilibrium in asymmetric rent-seeking contests," Journal of Public Economic Theory, vol.10, pp.317-327, 2008. 